\title{
High prevalence of Toxoplasma gondii oocyst shedding in stray and pet cats (Felis catus) in Virginia, United States
}

\author{
Emily L Lilly ${ }^{*}$ and Caroline D Wortham
}

\begin{abstract}
Background: The protozoan Toxoplasma gondii is the causative agent of toxoplasmosis, with complications varying from mental disease to death. While human infection can occur via ingestion of tissue cysts from infected meat, most human infection comes from oocysts. Cats are the only definitive host, and thus shedding of oocysts by cats provides the ultimate source of toxoplasmosis.

Methods: While most studies in the area use seroprevalence to monitor Toxoplasma incidence in cat populations, this provides only a history of infection. This study used PCR detection of oocysts from cat feces to more accurately estimate the numbers of cats producing oocysts and thus posing an active health risk. DNA sequencing was use to confirm the identity of the PCR products.

Results: Of the 49 cats tested, 9 yielded PCR products of the expected size. Six of the nine were determined by sequence analysis to be false positives, while three products were true positives. Overall, $6 \%$ of cats examined were found to be actively shedding oocysts.

Conclusions: The incidence of oocyst shedding in the cat population studied was significantly higher than expected and higher than found in most cat populations world-wide. Of equal importance, the primers tested were shown to produce PCR products of multiple sizes and non-target products of expected size. We detected false positives at a higher rate than true positives, emphasizing the need for confirmatory analysis. Further research may produce better protocols for Toxoplasma detection from cat fecal samples.
\end{abstract}

Keywords: Cat, Fecal, Felis catus, Molecular detection, Oocyst, Parasite, PCR, Prevalence, Toxoplasma gondii

\section{Background}

Toxoplasmosis, caused by the protozoan Toxoplasma gondii, can lead to encephalitis, retinitis, and myocarditis $[1,2]$. Among immuno-compromised individuals, toxoplasmosis is a leading cause of hospitalization and death [3]. Congenital toxoplasmosis affects an estimated 5000 newborns each year in the United States [4], resulting in prematurity, mental retardation, and ocular disease [5]. Acute maternal infection can also result in fetal loss or neonate death $[5,6]$. This is particularly concerning given that $85-89 \%$ of childbearing age women have no immunity to T. gondii [7], and are thus at risk of developing an acute infection if exposed to the parasite.

Chronic infection occurs in approximately $22.5 \%$ of the US population [7]. The latent infection appears to

\footnotetext{
*Correspondence: lillyel10@vmi.edu

Biology Department, Virginia Military Institute, Lexington, VA 24450, USA
}

pose no direct physical health risks, but it has been associated with increased rates of disturbing behavior, including homicide [8], suicide and other self-directed violence [9], as well as increased incidence of schizophrenia and other neuropsychiatric diseases [10].

Primary routes of acute human $T$. gondii infection include ingestion of tissue cysts in undercooked, contaminated meat, congenital infection through the placenta, and ingestion of oocysts from soil, water, or cat litter $[7,11]$. Oocysts are produced by $T$. gondii only through sexual reproduction in its definitive host, the cat [11-13]. Oocysts are shed in cat feces and can remain viable in soil and water samples for months to years [14]. Individuals with occupations requiring contact with soil in environments frequented by cats are significantly more likely to contract toxoplasmosis [7]. However, the more significant risk factor is contact with cats and cat litter. 
Owning just one cat increases the risk of toxoplasmosis, but having three or more kittens makes an individual over 70 times more likely to become infected with $T$. gondii [4]. While acute infection can be fatal to young kittens [12], cats may be asymptomatic [11], increasing the likelihood of accidental infection.

Toxoplasma gondii is ubiquitous in Virginia. Antibodies to T. gondii were present in the sera of $27 \%$ of tested lambs [15], $20 \%$ of tested dogs [16], and $27 \%$ of tested cats [17]. However, documentation of T. gondii antibodies could indicate prior exposure or a latent infection in which $T$. gondii is present only in tissue cysts [18]. In food animals such as lambs, tissue cysts represent a potential health risk for humans through meat consumption [15], but they are unlikely to pose a risk in a non-food animal like the cat. In cats, danger of infection exists only when the animal is actively shedding oocysts [11].

The majority of oocysts are produced shortly after the initial acquisition of the parasite, peaking within a month of initial infection [11,12]. Oocyte shedding generally lasts no more than 21 days [11,19], although it may recur with immunosuppression [20]. In comparative studies of blood serum and fecal assays, 0\% [21-25], 3\% [26], 4\% [27], and 6\% [28] of seropositive cats were found to have oocyte-contaminated feces. Thus, while serological testing may be applicable for determining parasite exposure, it is likely to vastly overestimate human health risk from cats.

Methods for determining oocyte presence in fecal samples include microscopy, mouse bioassay, and PCR $[11,13]$. Microscopy is time consuming and requires specialized training to visually identify $T$. gondii oocysts [13]. In addition, cyst-forming organisms with similar morphology must be differentiated with subsequent tests $[11,19]$. Mouse bioassay is more sensitive than microscopy [28], but requires the use of live mice and amplifies T. gondii, posing a biohazard. PCR is the most timeefficient of the three, requires only common molecular biology experience, easily differentiates $T$. gondii from other cyst forming eukaryotic parasites, and is highly sensitive $[13,27]$.

In this study, two previously developed sets of PCR primers [13,29-31] were used in combination with sequence confirmation to determine oocyte presence in cat feces collected throughout Rockbridge County, VA.

\section{Methods}

Fecal samples

Sixty unique fecal samples were collected from both pet and stray cats in Rockbridge County, VA. Domestic environmental conditions of the pet cats were defined as "indoor only," or "both indoor and outdoor." Cats living outside only were categorized as "stray."

\section{Coprologic diagnosis by PCR}

DNA was extracted from each sample using the QIAamp ${ }^{\circ}$ DNA Stool Mini Kit (Qiagen), with modifications to the extraction protocol as previously described [13]. Two sets of $T$. gondii specific primers (Table 1) were used in separate PCR reactions for every sample. Amplification followed the methodology of the reference paper. Universal bacterial 16S rRNA gene primers 27F and 1492R were used as positive controls to ensure that DNA extracts contained amplifiable DNA and were free of PCR inhibitors.

\section{Post amplification analysis}

PCR products were separated on agarose gels. When multiple bands were observed, bands of appropriate size for the primer set used were excised and extracted using QIAquick ${ }^{\circ}$ Gel Extraction. The purified products were sent for commercial DNA sequencing. The chromatographs were analyzed by hand for accuracy and the resulting sequences were subjected to nucleotide BLAST analysis [32].

\section{Results}

Positive control reactions amplified bacterial DNA from 49 of the fecal samples; $48 \%$ of which were from stray cats; $33 \%$ were from strictly indoor pets; and $11 \%$ from cats with both indoor and outdoor access. Gel electrophoresis showed that many of the PCR products produced with both primer sets, (up to 8-10 per sample), were not of the appropriate size, indicating non-specific amplification. Nine of the samples (18\%) yielded bands of predicted size, which were excised and sequenced. There was a high incidence of false positives: 6 of the 9 bands of appropriate size produced sequences identified as common fecal bacteria. Three samples, (from 1 stray and 2 indoor/outdoor pets), yielded sequences with high identity to known Toxoplasma gondii isolates, and were identified as positive for $T$. gondii oocytes. Thus, the incidence of oocyte shedding was determined to be $6 \%$ (3/49). One of the positive samples yielded positive results with both primer sets; the remaining two produced T. gondii products only with the primers developed by Costa et al. [29].

Table 1 Primers used for PCR detection of Toxoplasma gondii oocysts in fecal samples

\begin{tabular}{lll}
\hline Primer pair & TOX4/TOX5 & TOXF/TOXR \\
\hline Forward sequence & 5'-CGCTGCAGGGAG & 5'-GGAGGACTGGC \\
& GAAGACGAAAGTTG-3' & AACCTGGTGTCG-3' \\
Reverse sequence & 5'-CGCTGCAGACACA & 5'-TTGTTTCACCCGG \\
& GTGCATCTGGATT-3' & ACCGTTAGCAG-3' \\
Expected product size & $529 \mathrm{bp}$ & $129 \mathrm{bp}$ \\
Reference & {$[13,30,31]$} & {$[29]$} \\
\hline
\end{tabular}

Sequences of primers used in this study to detect Toxoplasma gondii. 


\section{Comparative analysis}

Twelve recent studies provided thirteen values for the percentage of cat fecal samples testing positive for Toxoplasma gondii oocysts (Table 2). For each study, a $x^{2}$ test was used to determine whether there were a statistically different number of positive fecal samples in Rockbridge County, VA, than would have been expected had the percent positive matched the reference study. The percent positive in this study (6\%) was significantly higher than expected when compared with 10 of the samples, comparable with 2, and less than expected when compared with the feral cat population in Ethiopia (when assayed by mouse bioassay, Table 2).

\section{Discussion}

The prevalence of Toxoplasma gondii oocyst shedding among the cat population in Rockbridge County, VA, was significantly greater than 10 of the 12 reference populations (Table 2). The only sample statistically higher than the current study was a population of feral cats from Ethiopia, where, $16 \%$ of cats tested copropositive by PCR, $22 \%$ tested copropositive by mouse bioassay, and $92 \%$ of cats tested seropositive for T. gondii antibodies, which is far above the world average of $30-40 \%$ seropositive cats [11].

T. gondii in Rockbridge County warrants further study to confirm the high prevalence and to determine potential causes and human impacts. In addition to studying cats, it would be prudent to sample soil and water as well, given that environmental T. gondii concentrations are higher when infected cats are present $[37,38]$.

Of equal concern, both primer sets published as specific to and diagnostic for Toxoplasma gondii yielded a substantial number of false positives. Fifty percent of
PCR products of relevant size were shown to be derived from fecal bacteria upon full sequence analysis. Additionally, multiple bands of irrelevant size were also produced, although PCR parameters were as described in the reference studies $[13,29,31]$. The false positives emphasize the need to use a second confirmation method on every apparently positive product. Gel electrophoresis can quickly eliminate products of vastly different size than expected, but a second method is required. Sibley et al., [39] used restriction fragment length polymorphism (RFLP) and nested-PCR to confirm T. gondii DNA sequence in PCR products. However, full sequencing provides a greater amount of data than RFLP, potentially yielding data for phylogenetic comparisons. Because of the ease and accuracy of DNA sequencing, it is recommended that similar studies use this method to confirm $T$. gondii presence and improve detection techniques.

\section{Conclusions}

The incidence of oocyst shedding in the cat population studied was significantly higher than expected and higher than found in most cat populations world-wide. Further research should be conducted to determine if the high prevalence of oocyst shedding cats is typical of the area. If so, measures in public education of at-risk groups may be warranted. Of broad importance, the primers tested were shown to produce false positives at a higher rate than true positives, emphasizing the need for confirmatory DNA sequence analysis. Current primers are tested against other common pathogens for use in clinical detection, but not against the numerous bacteria typically present in cat feces. Further research may produce better protocols for Toxoplasma detection from cat fecal samples.

Table 2 Comparison of the current study (6\% positive) with prior studies on Toxoplasma gondii oocysts in cat feces

\begin{tabular}{|c|c|c|c|c|c|c|}
\hline Location & Cat type & Method & Fecal positives (\%) & Difference from current & Significance ( $\mathrm{x} 2$ test) & Reference \\
\hline China & Stray & Mouse bioassay & $0 \%$ & Less & $p=0$ & [22] \\
\hline China & Stray & Mouse bioassay & $0 \%$ & Less & $p=0$ & [20] \\
\hline Egypt & Stray & Mouse bioassay & $0 \%$ & Less & $p=0$ & [21] \\
\hline Spain & Stray and pet & Microscopy & $0 \%$ & Less & $p=0$ & [18] \\
\hline Colombia & Stray & Mouse bioassay & $0 \%$ & Less & $p=0$ & [19] \\
\hline Europe & Stray and pet & Microscopy & $0.11 \%$ & Less & $p=0$ & [33] \\
\hline Switzerland & Stray and pet & PCR & $0.30 \%$ & Less & $p=0$ & [34] \\
\hline United States (CA) & Stray and pet & Microscopy & $0.90 \%$ & Less & $p=0.0001$ & {$[35]$} \\
\hline Canada (PEI) & Stray & Microscopy & $1.30 \%$ & Less & $p=0.003$ & {$[27]$} \\
\hline Finland & Stray & Microscopy/PCR & $1.50 \%$ & Less & $p=0.008$ & [26] \\
\hline Ethiopia ${ }^{a}$ & Stray & Microscopy & $5.50 \%$ & Comparable & $p=0.85$ & [28] \\
\hline Italy & Stray & PCR & $16 \%$ & Comparable & $p=0.06$ & [36] \\
\hline Ethiopia $^{a}$ & Stray & Mouse bioassay & $22.20 \%$ & More & $p=0.007$ & {$[28]$} \\
\hline
\end{tabular}

${ }^{a}$ The same cats were tested by both microscopy and mouse bioassay, with greater detection using mouse bioassay.

Comparison between current data and other measures of oocyst shedding in cat feces. 


\section{Competing interests}

Neither of the authors has any conflict of interests concerning the work reported in this paper.

\section{Authors' contributions}

CDW and ELL conceived and designed the experiment. CDW collected samples, performed molecular analyses, and helped to draft the manuscript. ELL conducted the sequence analysis and comparative prevalence analyses, and completed the manuscript. Both authors approved the final manuscript.

Received: 28 May 2013 Accepted: 14 August 2013

Published: 17 September 2013

\section{References}

1. Hill D, Dubey J: Toxoplasma gondii: transmission, diagnosis and prevention. Clin Microbiol Infect 2002, 8(10):634-640.

2. Blader I, Saeij J: Communication between Toxoplasma gondii and its host: impact on parasite growth, development, immune evasion, and virulence. APMIS 2009, 117(5-6):458-476.

3. Jones JL, Roberts JM: Toxoplasmosis hospitalizations in the United States, 2008, and trends, 1993-2008. Clin Infect Dis 2012, 54(7):e58-e61.

4. Jones JL, Dargelas V, Roberts J, Press C, Remington JS, Montoya JG: Risk factors for Toxoplasma gondii infection in the United States. Clin Infect Dis 2009, 49:878-884.

5. McLeod R, Boyer KM, Lee D, Mui E, Wroblewski K, Karrison T, Noble AG, Withers S, Swisher CN, Heydemann PT, Sautter M, Babiarz J, Rabiah P, Meier P, Grigg ME, the Toxoplasmosis Study Group: Prematurity and severity are associated with Toxoplasma gondii alleles (NCCCTS, 1981-2009). Clin Infect Dis 2012, 54(11):1595-1605.

6. Brughattas S, Ben-Abdallah R, Siala E, Souissi O, Maataug R, Aoun K, Bouratbine A: Case of fatal congenital toxoplasmosis associated with I/III recombinant genotype. Trop Biomed 2011, 28(3):615-619.

7. Jones JL, Kruszon-Moran D, Wilson M, McQuillan G, Navin T, McAulet JB; Toxoplasma gondii infection in the United States: seroprevalence and risk factors. Am J Epidemiol 2001, 154(4):357-365.

8. Lester D: Toxoplasma gondii and homicide. Psychol Rep 2012, 111(1):196-197.

9. Pedersen MG, Mortensen PB, Norgaard-Pedersen B, Postolache T: Toxoplasma gondii infection and self-directed violence in mothers. Arch Gen Psychiatry 2012, 69(11):1123-1130.

10. Fabiani S, Pinto B, Bruschi F: Toxoplasmosis and neuropsychiatric diseases: can serological studies establish a clear relationship? Neurol Sci 2013, 34(4):417-425.

11. Elmore SA, Jones JL, Conrad PA, Patton S, Lindsay DS, Dubey JP: Toxoplasma gondii: epidemiol, feline clinical aspects, and prevention. Trends Parasitol 2010, 26(4):190-196.

12. Dubey JP: Tachyzoite-induced life cycle of Toxoplasma gondii in cats. J Parasitol 2002, 88(4):713-717.

13. Salant H, Spira D, Hamburger J: A comparative analysis of coprologic diagnostic methods for detection of Toxoplasma gondii in cats. Am J Trop Med Hyg 2010, 82(5):865-870.

14. Lélu M, Villena I, Dardé ML, Aubert D, Geers R, Dupuis E, Marnef F, Poulle ML, Gotteland C, Dumètre A, Gilot-Fromont E: Quantitative estimation of the viability of Toxoplasma gondii oocysts in soil. Appl Environ Microbiol 2012, 78(15):5127-5132.

15. Dubey JP, Sundar N, Hill D, Velmurugan GV, Bandini LA, Kwok OC, Majumdar D, Su C: High prevalence and abundant atypical genotypes of Toxoplasma gondii isolated from lambs destined for human consumption in the USA. Int J Parasitol 2008, 38(8-9):999-1006.

16. Rosypal AC, Hill R, Lewis S, Braxton K, Zajac AM, Lindsay DS: Toxoplasma gondii and Trypanosoma cruzi antibodies in dogs from Virginia. Zoonoses Public Health 2010, 57(7-8):e76-e80.

17. Hsu V, Grant DC, Zajac AM, Witonsky SG, Lindsay DS: Prevalence of IgG antibodies to Encaphalitozoon cuniculi and Toxoplasma gondii in cats with and without chronic kidney disease from Virginia. Vet Parasitol 2011, 176(1):23-26.

18. Jones JL, Dubey J: Waterborne toxoplasmosis - recent developments. Exp Parasitol 2009, 124:10-25.

19. Lappin M: Update on the diagnosis and management of Toxoplasma gondii infection in cats. Clin Tech Small An P 2010, 25(3):136-141.

20. Malmasi A, Mosallanejad B, Mohebali M, Sharifian Fard M, Taheri M: Prevention of shedding and re-shedding of Toxoplasma gondii oocysts in experimentally infected cats treated with oral clindamycin: a preliminary study. Zoonoses Public Health 2008, 56(2):102-104.
21. Miró G, Montoya A, Jiménez S, Frisuelos C, Mateo M, Fuentes I: Prevalence of antibodies to Toxoplasma gondii and intestinal parasites in stray, farm, and household cats in Spain. Vet Parasitol 2004, 126(3):249-255.

22. Dubey JP, Su C, Cortés JA, Sundar N, Gomez-Marin JE, Polo L, Zambrano L, Mora LE, Lora F, Jimenez J, Kwok OC, Shen SK, Zhang X, Nieto A, Thulliez P: Prevalence of Toxoplasma gondii in cats from Colombia, South America and genetic characterization of T. gondii isolates. Vet Parasitol 2006, 141(1-2):42-47.

23. Dubey JP, Zhu XQ, Sundar N, Zhang H, Kwok OCH, Su C: Genetic and biologic characterization of Toxoplasma gondii isolates of cats from China. Vet Parasitol 2007, 145(3-4):352-356.

24. Al-Kappany YM, Rajendran C, Ferreira LR, Kwok OC, Abu-Elwafa SA, Hilali M, Dubey JP: High prevalence of toxoplasmosis in cats from Egypt: isolation of viable Toxoplasma gondii, tissue distribution, and isolate designation. J Parasitol 2010, 96(6):1115-1118.

25. Qian W, Wang H, Su C, Shan D, Cui X, Yang N, Lv C, Liu Q: Isolation and characterization of Toxoplasma gondii strains from stray cats revealed a single genotype in Beijing. China Vet Parasitol 2012, 187(3-4):408-413.

26. Jokelainen P, Simola O, Rantanen E, Näreaho A, Lohi H, Sakura A: Feline toxoplasmosis in Finland: cross-sectional epidemiological study and case series study. J Vet Diagn Invest 2012, 24(6):1115-1124.

27. Stojanovic V, Foley P: Infectious disease prevalence in a feral cat population on Prince Edward Island. Canada Can Vet J 2011, 52(9):979-982.

28. Dubey JP, Darrington C, Tiao N, Ferreira L, Choudhary S, Molla B, Saville W, Tilahun G, Kwok O, Gebreyes G: Isolation of viable Toxoplasma gondii from tissues and feces of cats from Addis Ababa. Ethiopia J Parasitol 2013, 99(1):56-58.

29. Costa J, Pautas C, Ernault P, Foulet F, Cordonnier C, Bretagne S: Real-time PCR for diagnosis and follow-up of Toxoplasma reactivation after allogeneic stem cell transplantation using fluorescence resonance energy transfer hybridization probes. J Clin Microbiol 2000, 38:2929-2932.

30. Homan WL, Vercammen M, De Braekeleer J, Verschueren $\mathrm{H}$ : Identification of a 200- to 300-fold repeticive 529 bp DNA fragment in Toxoplasma gondii, and its use for diagnostic and quantitative PCR. Int J Parasitol 2000, 30(1):69-75.

31. Salant H, Markovics A, Spira DT, Hamburger J: The development of a molecular approach for coprodiagnosis of Toxoplasma gondii. Vet Parasitol 2007, 146(3-4):214-220.

32. Altschul SF, Madden TL, Schaffer AA, Zhang J, Miller W, Lipman DJ: Gapped BLAST and PSI-BLAST: a new generation of protein database search programs. Nucleic Acid Res 1997, 25:3389-3402.

33. Schares G, Vrhovec MG, Pantchev N, Hermann DC, Conraths FJ: Occurrence of Toxoplasma gondii and Hammondia hammondi oocysts in the faeces of cats from Germany and other European countries. Vet Parasitol 2008, 152(1-2):34-45.

34. Berger-Schoch A, Herrmann D, Schares G, Müller N, Bernet D, Gottstein B, Frey C: Prevalence and genotypes of Toxoplasma gondii in feline faeces (oocysts) and meat from sheep, cattle and pigs in Switzerland. Vet Parasitol 2010, 177(3-4):290-297.

35. Dabritz HA, Miller MA, Atwill ER, Gardner IA, Leutenegger CM, Melli AC, Conrad PA: Detection of Toxoplasma gondii-like oocysts in cat feces and estimates of the environmental oocyst burden. J Am Vet Assoc 2007, 231(11):1676-1684.

36. Mancianti F, Nardoni S, Ariti G, Parlanti D, Giuliani G, Papini RA: Crosssectional survey of Toxoplasma gondii infection in colony cats from urban Florence (Italy). J Feline Med Surg 2010, 12(4):351-354.

37. Afonso E, Lemoine M, Poulle ML, Ravat MC, Romand S, Thulliez P, Villena I, Aubert D, Rabilloud M, Riche B, Gilot-Fromont E: Spatial distribution of soil contamination by Toxoplasma gondii in relation to cat defecation behaviour in an urban area. Int J Parasitol 2008, 38:1017-1023.

38. Aramini J, Stephen C, Dubey J, Engelstoft C, Schwantje H, Ribble C: Potential contamination of drinking water with $\mathrm{T}$. gondii oocysts. Epidemiol Infect 1999, 122(2):305-315.

39. Sibley D, Khan A, Ajioka J, Rosenthal B: Genetic diversity of Toxoplasma gondii in animals and humans. Philos T R Soc 2009, 364:2749-2761.

\section{doi:10.1186/1756-3305-6-266}

Cite this article as: Lilly and Wortham: High prevalence of Toxoplasma gondii oocyst shedding in stray and pet cats (Felis catus) in Virginia, United States. Parasites \& Vectors 2013 6:266. 